Institutions

Markets

Technologies

IMT

INSTITUTE

FOR ADVANCED

STUDIES

LUCCA
\#01

2016

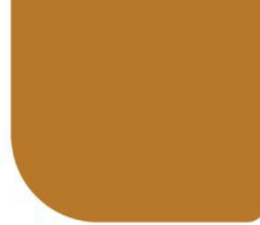

ISSN 2279-6894

IMT LUCCA EIC WORKING

PAPER SERIES 01

January 2016

\title{
Access to Medicines and European Market Integration
}

Fabio Pammolli

Armando Rungi 
ISSN 2279-6894

IMT LUCCA EIC WORKING PAPER SERIES \#01/2016

(C) IMT Institute for Advanced Studies Lucca

Piazza San Ponziano 6, 55100 Lucca

Research Area

Economics and institutional change

\section{Access to Medicines and European Market Integration}

\section{Fabio Pammolli}

IMT Institute for Advanced Studies Lucca \& CEDRM Foundation

\section{Armando Rungi}

IMT Institute for Advanced Studies Lucca 


\title{
Access to Medicines and European Market Integration
}

\author{
Fabio Pammolli \\ (IMT Lucca \& CERM Foundation)
}

\author{
Armando Rungi* \\ (IMT Lucca)
}

January 9, 2016

\begin{abstract}
In this paper we document a process of price convergence in the European market for pharmaceuticals and relate it to access to innovative medicines in individual countries. The EU is a peculiar case study, where free circulation of goods exists, but pricing policies are designed and implemented by Member States. Thanks to a unique census database on product sales and launches for fifteen EU countries, we detect a process of price convergence, both in nominal and in real terms. Therefore, we find that a faster rate of price convergence and a lower income per capita are associated with stronger delays in launches of new medicines. Moreover, country delays tend to be higher for innovative and first in class chemical compounds. Our results suggest that inefficiencies arise from drugs regulation, when countries widely differ in income per capita, public finance sustainability conditions, and regulatory frameworks. Policies of external reference pricing tend to exacerbate welfare losses. A policy of differential pricing is suggested, in order to take into account both therapeutic value and willingness to pay.
\end{abstract}

JEL classification: F15; I11; L65; L11; L51

Keywords: economic integration, price convergence, product launches, European Single Market, healthcare, pharmaceutical industry, pricing.

Financial support was provided by the project for Sustainable Welfare Innovation and Competition in Health (SWITCH). We thank Luca Maini for useful discussions and his contribution to the matching of data. We are grateful to CrisisLab Project and to several seminar participants. IMS Health provided access to data. Usual disclaimers apply.

*corresponding author: mail to armando.rungi@imtlucca.it. Laboratory for the Analysis of Complex Economic Systems, piazza San Francesco 19 - 55100 Lucca - Italy. 


\section{Introduction}

We study how market integration in the European Union can affect the diffusion of new medicines, in a context of separate National Systems of Regulation (see Gambardella, Orsenigo, Pammolli, 2000; McKelvey, Orsenigo, Pammolli, 2004).

The case of the European Union (EU) is peculiar. Despite striving for continental economic integration, each member country maintains its own pricing and reimbursement policies on pharmaceutical markets. Albeit fragmented, national regulations throughout the EU members share some core pricing and reimbursement mechanisms (Carone, Schwiers and Xavier, 2012). Most EU members rely on external benchmarking, for which a price limit in the domestic country can be set according to what other foreign countries already pay (external reference pricing).

However, national pricing policies originally designed for cost-containment in pharmaceutical expenditure can have spillovers in presence of interdependent markets (Danzon and Chao, 2012; Lanjouw, 2005), when companies choose to delay entering in low-price countries, in order to avoid undermining profits coming from high-price countries. Moreover, the current EU legal framework allows parallel imports from low-cost Member Countries. ${ }^{1}$

Preliminary evidence shows that, in the period 2002- 2012, the intra-EU pharmaceutical trade increased threefold, with respect to a mere $50 \%$ in overall manufacturing (Eurostat). This is consistent with an overall price convergence that we detect across European countries, as a removal of institutional barriers allows for arbitrage opportunities from countries where pharmaceuticals are the cheapest.

In general, the European Commission has only limited tasks in strengthening cooperation and coordination among member states, although the importance of cooperation has been enshrined in the Lisbon Treaty since 2009. However, an explicit reference to the principle of subsidiarity excludes the possibility of intervening at the European level to define the allocation of resources devoted to management of healthcare, which is left to single member States. ${ }^{2}$

In this context, there is a clear need to establish how relationships between market integration, prices and patients'access to medicine are evolving. To date, evidence has focused on small product samples, considering some selected countries or therapeutic markets, without a specific focus on the European common market.

We find evidence of a relatively fast market integration in the European pharmaceutical market after exploiting the census of pharmaceutical products provided by IMS Health MIDAS across 15 European countries, for which we possess the complete data on sales and volumes of all pharmaceutical products sold through the retail channel since 2001. We start by performing an aggregate analysis on national bundles of goods, finding that a process of price convergence is detected after accounting for possibly endogenous market dynamics, such as product churning and reallocation of products market shares. In a second stage we switch to molecule-level data in order to control for product quality, demanded volumes and national market competition, after the estimaton of quasi-hedonic prices. Hence, we further confirm that convergence is verified, in both nominal and real prices, for the overall sample and for products that are sold on the off-patent market only. However, we detect a strong heterogeneity in the speed of convergence across therapeutic submarkets.

Finally, we focus on the relationship between observed price convergence, as an indicator of market integration, and the sequence of country launches of innovative chemical compounds by pharmaceutical companies. We find that a faster therapeutic market integration correlates with longer country delays, even after controlling for the average manufacturing price convergence in Europe. Moreover, launches occur on average later in countries with lower incomes per capita. Interestingly, first-in-class compounds (i.e. compounds that exploit new pathways to treat a disease) tend to experience longer delays than other drugs.

\footnotetext{
${ }^{1}$ The Court of Justice of the European Union has established a policy of 'community exhaustion' of most forms of intellectual property rights. The legal rationale resides in the free circulation of goods set by the Treaty of Rome, establishing the European Economic Community (TEEC) in 1957. For more details, see Grigoriadis (2014).

${ }^{2}$ For more details, see also Towse et al. (2015).
} 
All our findings point to the existence of welfare-reducing effects arising from nationally fragmented regulations. In the presence of ever increasing continental integration, firms can respond strategically to preserve market fragmentation after lower expectations on profit margins, consequently reducing their capacity to recover from high $R \& D$ sunk costs. ${ }^{3}$ They launch new drugs selectively, where and when they are able to negotiate higher initial prices. They can also select by R\&D intensity, in therapeutic submarkets where expectations on competition are lower (Sutton, 1998). In this case, national regulations, originally designed for allowing wider access to healthcare, end up with a patients' access problem, which is welfare-reducing by country and/or therapeutic markets.

We argue that the European Union is a peculiar challenge for the design of an efficient pricing mechanism across countries, when regulation spillovers can cross national borders. The removal of any trade barriers within Europe makes the arbitrage from cheapest locations easier, pushing companies to respond strategically when selectively picking locations and therapies, hence trying to keep a level of market fragmentation that allows them to recover from R\&D sunk costs. Eventually, we argue that an ad hoc degree of market segmentation by country should be possible, as a second-best option.

It would be a Pareto improvement, as long as it takes into account incentives for pharmaceutical $\mathrm{R} \& \mathrm{D}$, therapeutic value and consumer welfare. ${ }^{4}$ Our evidence supports the necessity of a value-based pricing mechanism that takes into account heterogeneity within and across countries, combining both an assessment of therapeutic value and a consideration of patients'willingness to pay, which is in line with what is suggested by Danzon et al. (2013) and Towse et al. (2015). Also, a stronger role of the European Medicine Agency is needed, when assessing the therapeutic value of a drug, as it could reduce time to launch for more innovative drugs, avoiding longer negotiations between companies and single national authorities.

The paper is structured as follows. In the next Section we review existing literature related to our work. In Section 3 we introduce data and provide some descriptive statistics. In Section 4 we present evidence of price convergence, first on aggregate and then at the molecule level. In Section 5 we limit our investigation to newly marketed molecules and test access by price convergence and country-specific characteristics. Section 7 concludes.

\section{A review of existing literature}

To the best of our knowledge, ours is the first contribution that makes a systematic assessment of pharmaceutical market integration in the European Union, looking at its impact on the diffusion of new and innovative products in member countries.

In general, it is widely acknowledged that the establishment of a European Common Market initiated a process of continental economic integration leading to a generalized process of convergence in incomes and prices across Europe. Official data from Eurostat shows generalized price convergence for a representative bundle of goods in the European Union ${ }^{5}$ over the last two decades, which becomes even more pronounced when considering the access of new member countries after 2004. Price convergence is predicted by the Law of One Price (LOP), which states that, in the absence of transport costs and institutional barriers, a good must sell for the same price in all locations. In practice, prices will convergence across countries at different speeds, conditional on the speed of barrier removal and on local demand and supply peculiarities, showing a more or less volatile trend towards convergence rather than a perfect linear process. ${ }^{6}$

\footnotetext{
${ }^{3}$ For the relationship between $\mathrm{R} \& \mathrm{D}$ activity and market structure, including peculiarities of the pharmaceutical industry, we make reference to Sutton (1998).

${ }^{4}$ See Danzon et al. (2013) for a generalization of a value-based pricing mechanism that takes into account within and across countries heterogeneity for patients' willingness to pay.

${ }^{5}$ The coefficient of variation (\%) of a typical household price index reported by Eurostat reduces from $42.6 \%$ to $25.6 \%$ in the EU 27 countries in the period 1995 to 2012 . From $32.4 \%$ to $25.6 \%$ in the period 2001-2012, which is the one we consider for this contribution.

${ }^{6}$ For a seminal work on the conditional and unconditional Law of One Price, see among others Rogoff et al. (2001) who test on over 700 years of decreasing trade costs. More recently, after using microdata, the Law of One Price has been tested on subsets by industry and/or countries, taking into account implicit heterogeneity concealed by aggregate price indexes. To name a few: Goldberg and Verboven (2005) for the European automotive industry; Cecchetti, Rogers (2007) for a comparison between EU and US; Parsley and Wei (2001) for a test of the effects of political borders as limits
} 
However, existing literature provides mixed evidence of convergence when focusing on pharmaceutical markets, while encompassing more limited sets of countries and/or therapeutic markets. For example, Leopold et al. (2013) finds evidence of convergence but driven by single countries (Germany and Greece) in a sample of 10 on-patent medicines for 5 years and 15 countries. Kanavos and Sotiris (2011) observe price convergence for a set of 100 originator branded drugs in OECD countries but only after restricting analysis to newer prescription medicines compared with older medicines over a span of two years. Tymur (2011) finds convergence for the cardiovascular therapeutic class in five European countries in the period 1994-2003. Schulenburg et al. (2011) limit the analysis to ACE inhibitors reaching no conclusion on the effect of reference pricing mechanisms on country prices.

In contrast with the limited scope of previous studies, our paper makes a broad assessment of the European market integration thanks to the use of pharmaceutical census data provided by IMS Health. First of all, by including all therapeutic markets we can check for their relevance and weight on a single country's market. Then, we are able to include in our study both on-patent and off-patent products, since the competition arising once the window of intellectual property protection expires can itself be a driver of convergence. Following Danzon and Chao (2000), our estimates of quasi-hedonic prices on a long span of time across countries not only control for attributes of chemical compounds (pack, form, strength, age) marketed under different brands, but also allow us to concentrate on prices net of market reallocation dynamics (competition, demand elasticity).

As in previous works on diffusion of medicines, we assume that a delay in country launches of new and innovative drugs represents a limit to healthcare access by national consumers. Nowadays, pharmaceutical companies operate on a cross-country scale and face rather complex market choices. Although a company might want to launch a new product in as many countries as possible, to recover from high R\&D sunk costs, previous studies demonstrate how companies actually market new chemical compounds in less countries than expected, with delays that are conditional on both market and firmlevel characteristics. For example, Kyle (2007) shows how domestic status and previous experience in the local market are important determinants in explaining product launches, in addition to market characteristics. Danzon and Epstein (2012) find that launch timing and prices of new drugs are influenced by prices of already established products, which are in turn affected by a country's own regulatory system. Thus, they claim that external referencing policies adopted in high-price countries can be welfare-reducing for low-price countries. Once again using prices of established products as a proxy of regulation tightness, Kyle (2007) shows that firms headquartered in more regulated countries eventually reach fewer alternative market destinations and are also less likely to launch in further countries $^{7}$. More specifically, in the case of the Swedish market, Ganslandt and Maskus (2004) find that firms reduce prices by $12-19 \%$ for products that are subject to competition from parallel imports in the period 1994-1999. With a global perspective, Lanjouw (2005) studies how world differences in legal and regulatory policies affect whether new drugs are marketed in a country, and how quickly they reach consumers. She finds that only less than one-half of new chemical compounds are eventually marketed in all countries. Moreover, a lag of six or seven years can pass from one country launch to the following one.

In the case of the European Union, we estimate comparable lags for countries' launch hazards of new chemical compounds. However, we also find that these launch hazards are correlated with a faster price convergence of the respective therapeutic markets, i.e. with a stronger market integration. This result is robust after including firms and market characteristics. We argue that the force of European market integration is a further determinant of possible country delays in health care access that has been neglected until now.

In line with previous findings, we also find that lower expected prices are correlated with longer delays. Here, we argue, prices of established products can be a poor proxy of country regulation tightness, as they can be mainly affected by local competitive pressures. We confirm, however, that low-income countries suffer on average from higher delays than richer countries, also within the European Union.

\footnotetext{
to the LOP that add to geographical distances.

${ }^{7}$ Several works have systematically investigated the peculiarities of cross-national static differences in drug prices. See for example Danzon and Furukawa (2011) for generic drugs, or Danzon and Chao (2002) for the overall effect of national regulatory regimes. The scope of our contribution is however to look at dynamic price differences.
} 
Eventually, for a more efficient pricing policy in presence of negative spillovers, arising from national regulations, several studies call for some form of Ramsey (1927) pricing mechanism, which would allow companies to discriminate explicitly on the basis of local demand and income characteristics (Malueg and Schwars, 1994; Danzon and Towse, 2003; Szymanski and Valletti, 2005; Jack and Lanjouw, 2005). More recently, Danzon et al. (2015) propose the adoption of a unique framework that could combine an evaluation of therapeutic value, while following differential pricing mechanism after patients' willingness to pay, within and across countries. In line with these works, we argue that a national pricing policy is specifically needed also within the European Single Market, which shall take into account consumers' welfare without disregarding companies' economic incentives. By balancing these two objectives, a policy granting some form of explicit price discrimination to companies might allow for an overall Pareto improvement.

\section{Data description}

For the purpose of our analysis, we exploit a census of international product- and molecule-level data collected by IMS Health, a consultancy firm, on quarterly revenue and volume sales over the period from 2001Q3 to 2013Q1. Our sample includes 15 countries that are part of the European Common Market $^{8}$, where we can separate retail sales from hospital sales, and where on-patent and off-patent status is reported over the entire period of analysis. We exclude sales to hospitals from our analysis because we cannot exclude ex-post discounts that are dependent on actual products usage. We end up with a sample of 6,773 chemical compounds that are marketed under 32,683 international products, either on-patent or off-patent, for all therapeutic classes.

An important sample feature for our analysis is that details on retail sales and volumes are reported by IMS Health as ex-manufacturer levels. Therefore, calculated prices do not need further adjustments for national differences in taxation and pharmacy markups.

Our basic unit of observation is the chemical compound (molecule), which is the unique active ingredient that can be sold under different formulations, packages and strength, both within a country and across countries. Hence, in the following analysis we will consider packages, formulations, and strength as attributes of the same unique chemical compound. Sold quantities are originally expressed as standard units ${ }^{9}$, which allow a comparison of sales and prices across solid and liquid formulations of the same medication.

We calculate molecule prices for a single country as the sales-weighted average price of all moleculerelated products marketed in that country. Since we also include in our study countries that still adopt their own currencies and not the euro, we convert original sales from national currencies using quartely exchange rates provided by the European Central Bank to obtain nominal prices. Furthermore, we obtain real prices after conversion by using quarterly real effective exchange rates (REER) from Darvas (2012).

For the second part of our contribution, where we analyze the effects of price convergence on access to innovative drugs, we identify a subset of 304 on-patent molecules (and 473 related products) that are launched for the first time in our sample of countries after 2001Q3. Note that these products could still have been first launched in a country outside our sample. However, we believe this is irrelevant for our results as we are mostly interested in the determinants of specific country launches, rather than the determinants of first absolute launches.

Compounds newly launched in the European Union are then classified following what is done by Lanthier et al. (2013), which covers new active ingredients approved by Food Drug Administration (FDA), for marketing in the United States ${ }^{10}$. The classification includes three categories in descending

\footnotetext{
${ }^{8}$ In the final sample we have 10 members of the Euro area (Austria, Belgium, Germany, Spain, Finland, France, Greece, Ireland, Italy, Portugal) and 5 countries that still adopt their own currencies (Czech Republic, United Kingdom, Hungary, Poland, Slovak Republic). Originally, data for sales are provided in national currencies.

${ }^{9} \mathrm{~A}$ standard unit is the equivalent in millilitres of liquid preparations for a solid dosage of one tablet. For details on definitions peculiar to health markets, see for example OECD (2014).

${ }^{10}$ The novelty of this classification stands in the review of sections for 'description' and 'clinical pharmacology' of approved labeling by the Center for Drug Evaluation and Research (CDER). A cross-check for scientific validity of the classification was made by experts working for CDER and FDA. For further details, see the Appendix B in Lanthier et
} 
order of innovation: i) first-in-class; ii) advance-in-class and iii) addition-to-class. In our sample we find about 200 active ingredients marketed both in the EU sample countries and in US. Descriptive statistics of launched molecules are reported in Table 4 and Table 5.

Macroeconomic data come from Eurostat regarding countries' GDP per capita and overall price convergence. The latter is already reported in official Eurostat data as the evolution of single countries' Purchasing Power Parities (PPP) relative to the rest of the European Union.

\section{Price convergence}

\subsection{National baskets of medicines}

In order to verify if a process of the European market integration is detected for the pharmaceutical industry, and how fast it is, we proceed by building price indexes for national baskets of medicines, and verify if they converge over time towards a European average.

For this purpose, we build a country-specific Laspeyres price index for each EU member country, in the form:

$$
P_{c t}=\frac{\sum_{s} p_{s c t+1} q_{s c t}}{\sum_{s} p_{s c t} q_{s c t}}
$$

where $p_{\text {sct }}$ and $q_{\text {sct }}$ are respectively price and quantity sold (in standard units) of product $s$ in country $c$ and quarter $t$. The benefit of adopting a Laspeyres Index resides in the possibility to exclude reallocation dynamics underlying the pharmaceutical market, focusing only on the within price variation of each product, and taking fixed the quantity consumed at the period before. To obtain nominal prices we convert with nominal quarterly exchange rates to euro when the country is not part of the euro-area, whereas to obtain real prices we convert with real effective exchange rates (REER) from Darvas $(2012)^{11}$. Then, we build a similar index for the total market represented by all 15 countries in our sample, $P_{E U t}$, considering products sold in at least one country.

In order to follow the evolution of prices in the European Single Market, we are interested in tracking the ratio $P R_{c t}=P_{c t} / P_{E U t}$, which in the case of perfect convergence of one country $c$ to the rest of Europe is equal to one, since the 'representative' medicine would sell at the same price in each country.

In Figure 1, we report visual evidence of this time trend for real prices only, whereas in Table 1 we test the existence of a unit root, first for all products, then excluding protected products, for both nominal and real prices. The separate test for off-patent status allows us to control that the process of convergence is not entirely driven by expiration of patent rights, after competition coming from generics producers. For our test, we adopt the procedure set by Levin, Lee and Chu (2002) of convergence over longitudinal observations. ${ }^{12}$ In our case we have a panel of 15 countries observed over 46 quarters. Hence, as countries' ratios to the EU average approach unity, they are reducing distances from the others in the integrated market and the null hypothesis for the existence of a unit root is rejected. On aggregate, we find a process of economic integration, for which prices are aligning across national borders. The process of price convergence is slightly more statistically significant (i.e. the t-statistics are higher) in the case of real prices, after deflating for manufacturing real-effective exchange rates (REER).

\footnotetext{
al. (2013).

${ }^{11}$ Darvas (2012) built real effective exchange rates (REERs) for 178 countries. They are made publicly available by Bruegel, the Brussels-based economic think tank. Among the alternative methodologies provided there, we choose the monthly indices for the manufacturing sector considering trade in euro. Since we have quarterly series for the pharmaceutical industry, we average montly REERs by quarter.

${ }^{12}$ For previous applications of this procedure to assess price convergence in the European Single Market, see Goldberg and Verboven (2003) in the case of the EU automotive industry, and Fischer (2009) for a comparison this and alternative approaches. Tymur (2011) applied the methodology to test the cardiovascular submarket in five EU countries.
} 
Figure 1: Visual evidence of real price convergence, all products, Laspeyres index ratio over 2001Q3 - 2013Q1

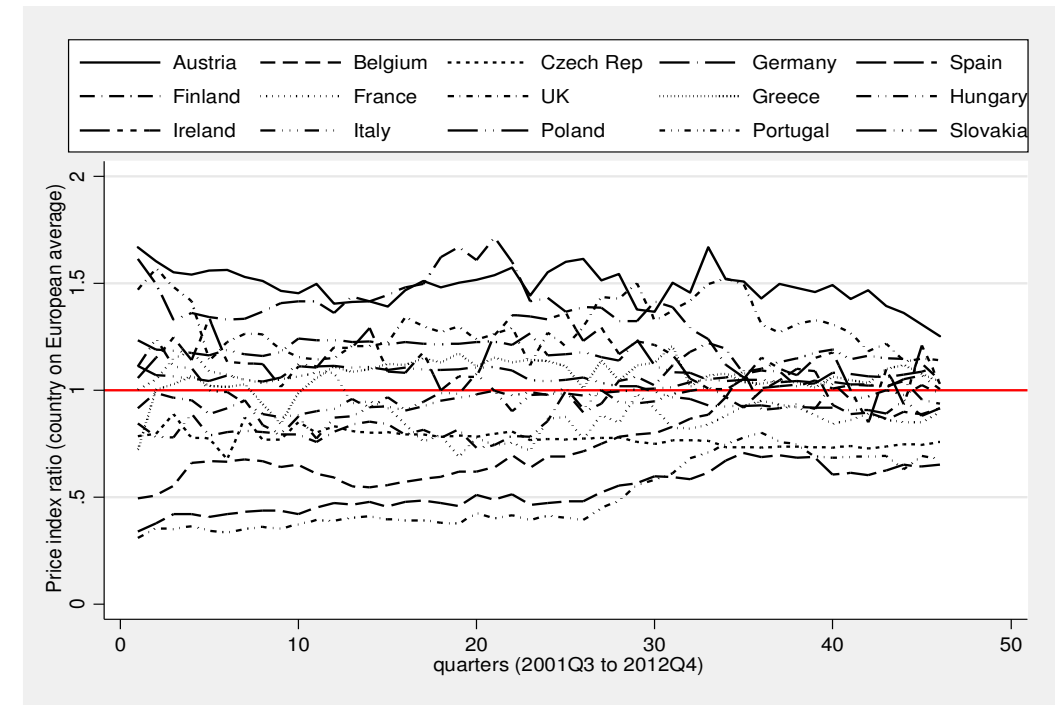

Note: Price Index ratio is built as a ratio between a national Price Index and an all-countries Price Index.

\subsection{Price convergence at the molecule-level}

In a cross-country context, an accurate measurement of intertemporal price differences has to take into account both product and country peculiarities. Country price dispersions, either within a country or across countries, can be due to quality differences. A common solution is to estimate hedonic prices that are able to catch and isolate the contribution of product attributes from market prices. This is particularly relevant in the case of the pharmaceutical industry, where the main object of analysis is a chemical compound, generally sold under different product names, with different dosages, packages and implicit therapeutic strength. Moreover, imperfect competition among products/molecules with different qualities is further exacerbated by the recognition of patent rights to manufacturers, which makes intertemporal and cross-national price differences sensitive to switches from protected to unprotected status, after which the degree of competition increases and prices decrease.

That is why we adopt a (quasi-)hedonic empirical strategy, with a system of two equations for demand and supply features. ${ }^{13}$ In the end, we will exploit latter estimates of hedonic prices for testing convergence, eventually net of locally observed demand and supply characteristics.

We start testing a simultaneous equation system (SEM), assuming that price and quantity may be endogenous, in the form ${ }^{14}$ :

$$
\begin{aligned}
& \ln p_{m(k) c t}=p\left(Z_{m(k) c}, C_{m(k) c t}\right) \\
& \ln q_{m(k) c t}=q\left(p_{m(k) c t}, T_{k}, H_{c}\right),
\end{aligned}
$$

\footnotetext{
${ }^{13}$ The use of a spurious hedonic regression that includes also variables for the extent of competition is justified by the peculiarity of the pharmaceutical industry, with a high monopolistic power. For previous applications, see also Danzon and Chao (2000).

${ }^{14}$ In this we follow a two-stage least squares procedure suggested by Zellner and Theil (1962).
} 
Table 1: Unit root tests for beta-convergence of country vs European price indexes

\begin{tabular}{lr|r}
\hline & \multicolumn{1}{c|}{ All products } & \multicolumn{1}{c}{ Off-patent } \\
\hline \hline Nominal prices & $-9.992 * * *$ & $-9.956^{* * * *}$ \\
\hline Adjusted t-statistic & \\
Real prices & $-14.763 * * *$ & $-14.866^{* * * *}$ \\
\hline Adjusted t-statistic & $* * *$ stands for $\mathrm{p}<.001$
\end{tabular}

where $p_{m(k) c t}$ is the $m$ th molecule price in therapeutic class $k$, sold in country $c$ and time $t ; q_{m(k) c t}$ is its sold quantity expressed in standard units; $Z_{m(k) c}$ is a set of quality controls including strength, age, form and pack for the $m$ th molecule in therapeutic class $k$ sold in country $c$; $C_{m(k) c t}$ is a set of controls for competition including the (log of) number of generic competitors present in country $c$ at time $t$, and the (log of) number of therapeutic substitutes in $c$ at time $t$ in category $k ; T_{k}$ and $H_{c}$ are respectively a set of therapeutic and country fixed effects for time-invariant characteristics, which may catch among others he effect of cross-country differences in regulations. Results for both nominal and real prices are reported in Table 2 .

In general, we observe that results for series of nominal and real prices are different in magnitude of coefficients, but similar in terms of signs and statistical significance. Among molecules attributes, the variety offered in strength and form is significantly correlated with a higher price, as expected. A higher range of possible prescriptions allows for a better use of an effective drug and a higher implicit value. A larger variety of product attributes is also a way for the firm to push back against price convergence. Marketing the same product in two countries in a different form or dosage is a way for the firm to artificially raise a trade barrier, which might allow them to price-discriminate more effectively, and therefore keep prices higher. Conversely, firms might be more willing to engage in these practices if the drug in question is particularly profitable, so this coefficient might mask some unobservable quality of the product. Molecule age is correlated to lower prices, consistent with the hypothesis of a therapeutic life-cycle, with newer molecules that are more effective than older ones. The effect of molecule age on prices seems to be more important on real prices, probably due to the existence of an integrated market with a unique product life-cycle across national borders.that is better caught after taking into account purchasing power parities by consumers.

Market competition from a larger set of generic competitors significantly lowers prices, in line with expectations and what is observed by Danzon and Chao (2000), whereas the presence of other therapeutic substitutes within an ATC 3-digit classification has a positive coefficient. This counterintuitive result can be due to a 'love of variety' effect in the presence of monopolistic competition. In other words, after already controlling in our specification for the presence of competitors that reportedly drives down molecule prices, having more medications within the same therapeutic category implies that national healthcare authorities acknowledge those products as being more differentiated, while addressing the same category of patients. Hence, the therapeutic submarket has an implicit lower elasticity of substitution that allows producers to sell at higher prices.

The quasi-hedonic empirical model further allows for an estimation of overall elasticities of demand to prices, reported on the first line of second equation in Table 2 . They are very similar for both nominal and real price series (about .80), and they permit us to derive net prices, also of market reallocation dynamics and of local demand characteristics. 
Table 2: Quasi-hedonic price regression, simultaneous demand and supply for nominal and real prices

\begin{tabular}{|c|c|c|}
\hline & $\begin{array}{c}\text { SEM } \\
\text { Nominal prices }\end{array}$ & $\begin{array}{c}\text { SEM } \\
\text { Real prices }\end{array}$ \\
\hline \multicolumn{3}{|l|}{ First equation } \\
\hline \multicolumn{3}{|c|}{ Dependent variable: (log of) molecule price } \\
\hline \multicolumn{3}{|l|}{ QUALITY } \\
\hline \multirow[t]{2}{*}{ (log of) strength } & $.059 * * *$ & $.048 * * *$ \\
\hline & $(.006)$ & $(.006)$ \\
\hline \multirow[t]{2}{*}{ (log of) age } & $-.024 * * *$ & $-.062^{* * * *}$ \\
\hline & $(.009)$ & $(.010)$ \\
\hline \multirow[t]{2}{*}{ (log of) form } & $.041^{* * * *}$ & .031 *** \\
\hline & $(.005)$ & $(.004)$ \\
\hline \multirow{2}{*}{ (log of) pack } &. .001 & -0.007 \\
\hline & $(.003)$ & $(.025)$ \\
\hline \multicolumn{3}{|l|}{ COMPETITION } \\
\hline \multirow[t]{2}{*}{ (log of) generic competitors } & $-.435 * * *$ & $-.300 * * *$ \\
\hline & $(.095)$ & $(.089)$ \\
\hline \multirow[t]{2}{*}{ (log of) therapeutic substitutes } & $.095 * * *$ & $.077 * * *$ \\
\hline & $(.012)$ & $(.012)$ \\
\hline \multirow[t]{2}{*}{ Constant } & $-1.001 * * *$ & $-.807 * * *$ \\
\hline & $(.398)$ & $(.140)$ \\
\hline Adjusted R-squared & .149 & .407 \\
\hline \multicolumn{3}{|l|}{ Second equation } \\
\hline \multicolumn{3}{|c|}{$\overline{\text { Dependent variable: }}$ (log of) standard units } \\
\hline (log of) molecule price & $\begin{array}{r}-.710 * * * \\
(.054)\end{array}$ & $\begin{array}{r}-.933 * * * * \\
(.020)\end{array}$ \\
\hline \multirow[t]{2}{*}{ Constant } & $12.595 * * *$ & $12.892^{* * * *}$ \\
\hline & (3.454) & $(.3550)$ \\
\hline Therapeutical categories fixed effects & Yes & Yes \\
\hline Country fixed effects & Yes & Yes \\
\hline Adjusted R-squared & .417 & .487 \\
\hline N. quarters & 46 & 46 \\
\hline N. molecules & 6,773 & 6,773 \\
\hline
\end{tabular}

*** stands for $\mathrm{p}<.001$. Robust standard errors in parentheses. 
By now we are ready to employ previous estimates of quasi-hedonic prices, which we obtain as residuals by combining eqs. 2 and 3 , to test molecule price-convergence. The baseline equation is the following:

$$
\Delta \ln p r_{m(k) c t}=\alpha_{m(k) c}+\beta \ln p r_{m(k) c t-1}+\sum_{l=1}^{L} \gamma_{l} \Delta \ln p r_{m(k) c t-l}+\delta t+\varepsilon_{m(k) c t},
$$

where the dependent variable $\Delta \ln p r_{m(k) c t}$ is the growth rate of country price ratios, calculated as the ratio between price $\left(p_{m(k) c t}\right)$ of molecule $m$ belonging to class $k$, marketed in country $c$ at time $t$, and an all-countries average price $\left(p_{m(k) E U t}\right)$ for the same molecule. As in the aggregate exercise of the previous section, a decreasing ratio implies a convergence of the country price towards the Law of One Price. ${ }^{15}$ Perfect market integration would imply price ratios equal to 1.

Regressors include the initial level of the same price ratio and a set of lags in growth rates $(l \epsilon L)$. A time trend $t$ and country-molecule fixed effects $\left(\alpha_{m(k) c}\right)$ are included for controlling time-invariant molecule features. The coefficient $\beta$ is the main parameter of interest as it gives us an estimate for the speed of (beta-)convergence. A half-life shock to price ratios can be calculated by $-\ln (2) / \ln (1+\beta)$, which is the time it would take for an impulse response to a unit shock to dissipate by half. If there were no convergence, the shock would be permanent.

To determine the more efficient number of lags $L$ to include in our estimation, we follow Campbell and Perron (1991)'s top-down approach, reducing the number of lags until reaching statistical significance. We end up with an $\operatorname{AR}(1)$ process of $L=1$. In Table 3 we report nested results before reporting the full baseline specification.

Table 3: Molecule price convergence, all products, nominal and real prices nested specifications

\begin{tabular}{|c|c|c|c|c|c|c|}
\hline $\begin{array}{l}\text { Dependent variable: } \\
\Delta(\log \text { of) price_ratio ikt }\end{array}$ & Nominal prices & Real prices & $\begin{array}{c}\text { Nominal prices } \\
\& \text { trend }\end{array}$ & $\begin{array}{l}\text { Real prices \& } \\
\text { trend }\end{array}$ & $\begin{array}{c}\text { Nominal prices } \\
\& \text { trend \& fixed } \\
\text { effects }\end{array}$ & $\begin{array}{c}\text { Real prices \& } \\
\text { trend \& fixed } \\
\text { effects }\end{array}$ \\
\hline (log of) price_ratio ${ }_{\text {ikt-1 }}$ & $\begin{array}{r}-.041^{* * *} \\
(.003)\end{array}$ & $\begin{array}{r}-.035^{* * *} \\
(.003)\end{array}$ & $\begin{array}{r}-.062^{* * *} \\
(.004)\end{array}$ & $\begin{array}{r}-.050^{* * *} \\
(.004)\end{array}$ & $\begin{array}{r}-.091^{* * *} \\
(.008)\end{array}$ & $\begin{array}{r}-.082^{* * *} \\
(.009)\end{array}$ \\
\hline$\Delta(\log$ of $)$ price_ratio $o_{\text {ikt-1 }}$ & $\begin{array}{r}-.030^{* * *} \\
(.010)\end{array}$ & $\begin{array}{r}-.027^{* * *} \\
(.008)\end{array}$ & $\begin{array}{r}-.057^{* * *} \\
(.012)\end{array}$ & $\begin{array}{r}-.032^{* * *} \\
(.009)\end{array}$ & $\begin{array}{r}-.061^{* * *} \\
(.010)\end{array}$ & $\begin{array}{r}-.050^{* * *} \\
(.011)\end{array}$ \\
\hline trend & & & $\begin{array}{r}.002 \\
(.005)\end{array}$ & $\begin{array}{r}-.002^{* * *} \\
(.001)\end{array}$ & $\begin{array}{r}.002 \\
(.006)\end{array}$ & $\begin{array}{r}-.002^{* * *} \\
(.001)\end{array}$ \\
\hline Molecule*country fixed effects & No & No & No & No & Yes & Yes \\
\hline Therapeutic clusters & Yes & Yes & Yes & Yes & Yes & Yes \\
\hline N. quarters & 46 & 46 & 46 & 46 & 46 & 46 \\
\hline N. molecules & 6,773 & 6,773 & 6,773 & 6,773 & 6,773 & 6,773 \\
\hline Adj R-squared & .031 & .031 & .029 & .023 & .032 & .024 \\
\hline Half-life of a shock (quarters) & 16.58 & 19.45 & 10.83 & 13.51 & 7.26 & 8.10 \\
\hline (in years) & 5.53 & 6.48 & 3.61 & 4.50 & 2.42 & 2.70 \\
\hline
\end{tabular}

$* * *$ stands for $\mathrm{p}<.001$, robust standard errors in parentheses.

\footnotetext{
${ }^{15}$ By construction, price ratios imply that a product is sold at least in two country markets in the same period. This excludes entry and exit of chemical entities, which can be non-synchronized across markets. In fact, the possible endogenous entry of new medicines is the object of following analyses.
} 
In all nested specifications we detect a process of price convergence. Half-life shocks range from 2.5 to 6.5 years, faster in columns 6 and 7 when we introduced molecule-country fixed effects, possibly catching some cross-border differences for different local marketing strategies by companies.

On the other hand, we detect negative time trends when testing for real prices, i.e. after controlling for countries' purchasing power parity. We cannot exclude that nominal prices are more affected by volatility of nominal exchange rates, especially when including in the same sample both members and non-members of the Eurozone, which can be subject or not to monetary policy adjustments. Eventually, we adopt as a baseline the results in column 7, where a significant negative trend is detected after deflation. We conclude that a process of price convergence across countries is confirmed also at the molecule level, for real prices, and that a slight negative time trend indicates the convergence towards the average is faster for higher prices, which on average offsets the increase in prices of cheaper pharmaceutical compounds.

In order to account for the different compositions of the national pharmaceutical basket of pharmaceutical products, we now estimate eq. 4 at the ATC 3-digit level, which is the level of disaggregation at which we assume a certain degree of homogeneity in the submarket exists in order to partition the entire pharmaceutical market. We report a visual evidence of the assessed heterogeneity in speeds of economic integration in Figure 2 for real molecule prices.

Figure 2: Visual evidence of estimates of molecule price convergence by therapeutic submarkets

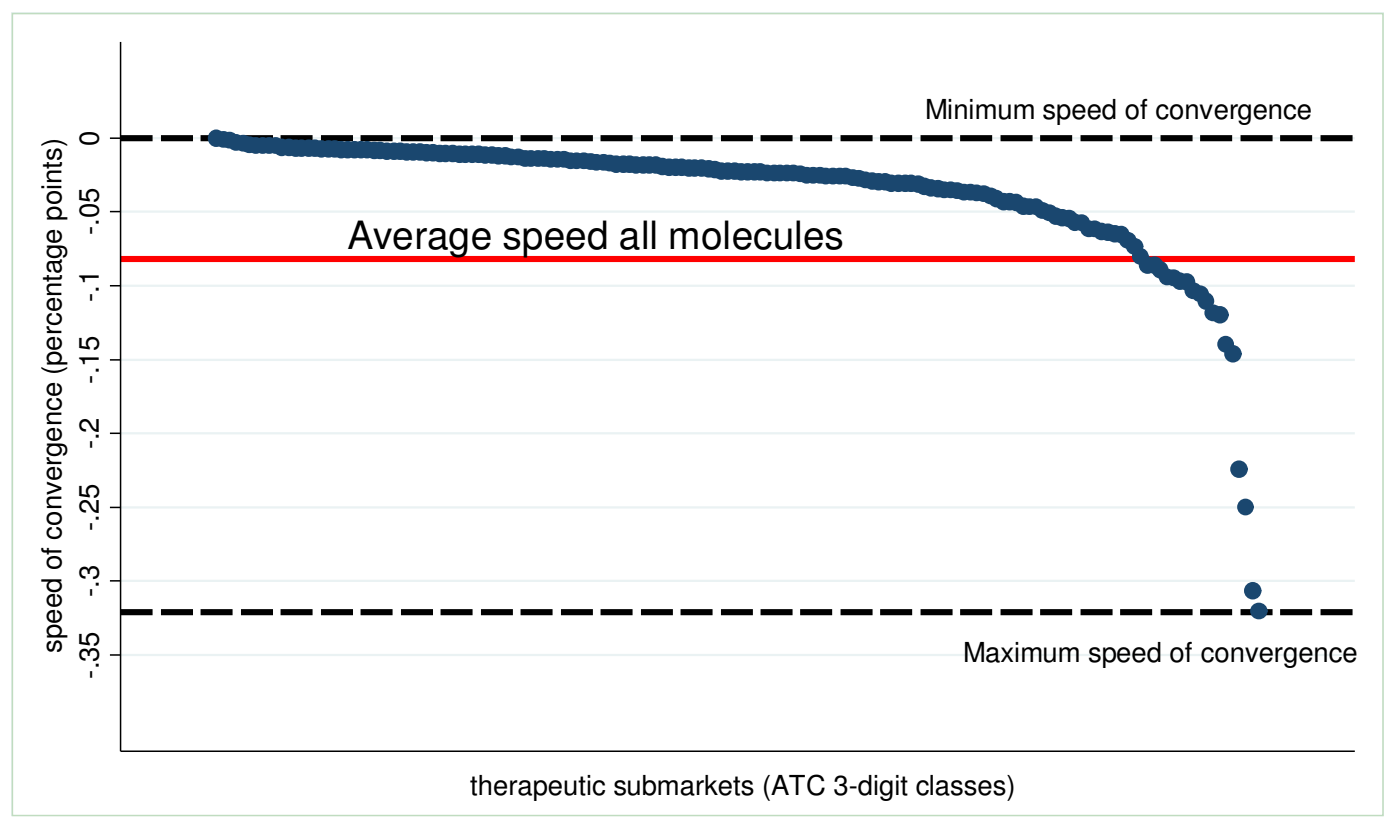

Note: Each point is a therapeutic market (ATC 3-digit) estimate, all statistically significant at least at $10 \%$, with robust standard errors.

Indeed, a noteworthy dispersion of therapeutic estimates is registered around the cross-therapeutic average represented here by the red line located at -.082 and borrowed from the last column of Table 3 . Among the least convergent therapeutic classes we find Antipsychotics (N05A), Anxiolytics (N05B), Hormonal contraceptives (G03A) and Drugs used in addictive disorders (N07B). Among the most convergent, we find Peripheral vasodilators (C04A), Drugs for obstructive airway diseases (R03A, R03B), and Antiemorrhagics (B02A, B02B). Notably, no therapeutic class reports positive coeffients (i.e. divergence), although some of them come very close to zero, but all with negative coefficients (i.e. convergence) with statistical significance. 
We conclude that a generalized process of market integration at the continental level is in progress, albeit different in speed by therapeutic submarkets, once we control for local demand and supply characteristics following quasi-hedonic prices. The rate of convergence in prices is so different across therapeutic submarkets that the half-life shocks can range from 2 years to 6 centuries. Namely, besides submarkets that still show a high level of market fragmentation, there are others that if left alone would reach perfect integration very soon, for which a medicament would be sold at the same (real) price throughout Europe.

This is not completely surprising, as this was the expected outcome after the establishment of a European Single Market, due to the removal of tariff and non-tariff barriers and the free circulation of goods and of a less-than-perfect free circulation of production factors like capital and labor. A process of price convergence in the pharmaceutical industry is not necessarily bad news. It becomes a problem if it is detrimental to the welfare of patients, in a market that is regulated on purpose to allow as wide as possible access to medicines in the presence of high $R \& D$ sunk costs by companies. In the next section we will assess which dimensions it can delay or prevent access to medicines across countries and therapies.

\section{$5 \quad$ Is market integration affecting medicine diffusion?}

\subsection{Some stylized facts}

In the previous sections we established that a process of market integration for pharmaceutical products does occur in the European Union. Now we want to test whether a higher level of market integration correlates with access to medicines, once affecting a company's decision in its sequence and timing of country launches.

From our complete sample we identify a subset of 304 newly protected chemical compounds that have been launched during or after 2001Q3 for the first time in at least one of the $15 \mathrm{EU}$ sample countries. Note here that since we are not interested in determinants of the first absolute launch after clinical scrutiny, we exclude from our analysis medications that could be already available elsewhere but not sold in any of our sample countries. What we assume at this stage is that a company has already decided to market an innovative molecule in Europe, hence it has only to decide the sequence of country launches that better maximizes its profits.

Table 4: Countries of first launch and further diffusion

\begin{tabular}{l|rr|rr}
\hline \multicolumn{5}{c}{ Launch of molecules and country diffusion } \\
\hline & $\begin{array}{r}\text { Launched } \\
\text { from } \\
200103\end{array}$ & $\%$ & $\begin{array}{r}\text { Diffusion as } \\
\text { in 2013Q1 }\end{array}$ & $\%$ \\
\hline Country & 15 & $4.94 \%$ & 247 & $81.25 \%$ \\
\hline Austria & 2 & $0.66 \%$ & 146 & $48.03 \%$ \\
Belgium & 8 & $2.63 \%$ & 184 & $60.53 \%$ \\
Czech Republic & 120 & $39.80 \%$ & 274 & $90.13 \%$ \\
Germany & 7 & $2.30 \%$ & 158 & $51.97 \%$ \\
Spain & 28 & $10.20 \%$ & 200 & $65.79 \%$ \\
Finland & 6 & $1.97 \%$ & 169 & $55.59 \%$ \\
France & 80 & $26.32 \%$ & 220 & $72.37 \%$ \\
United Kingdom & 5 & $1.64 \%$ & 190 & $62.50 \%$ \\
Greece & 2 & $0.66 \%$ & 171 & $56.25 \%$ \\
Hungary & 6 & $1.97 \%$ & 183 & $60.20 \%$ \\
Ireland & 5 & $0.66 \%$ & 151 & $49.67 \%$ \\
Italy & 14 & $4.61 \%$ & 177 & $58.22 \%$ \\
Poland & 5 & $1.64 \%$ & 116 & $38.16 \%$ \\
Portugal & 1 & $0.00 \%$ & 208 & $68.42 \%$ \\
\hline Slovak Republic & 304 & $\mathbf{1 0 0 . 0 0 \%}$ & & \\
\hline \hline
\end{tabular}

In Table 4 we provide some descriptive statistics on our subset of molecules. The first and second columns show how many molecules were launched first in each country, whereas the third and fourth 
Figure 3: A median sequence of country launches, delays after first launch in Germany

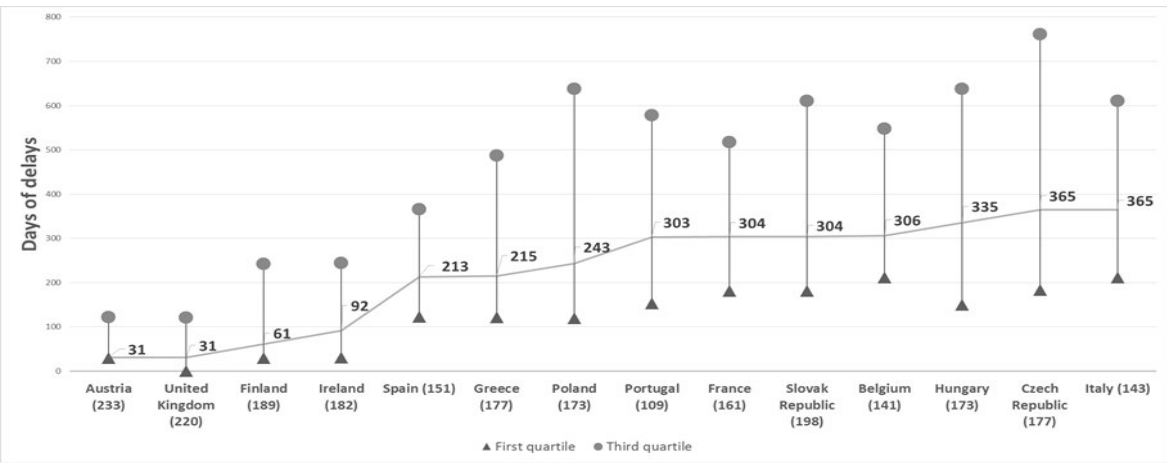

Note: Median between first and third quartiles (on the graph) of lags by country from launch in the German market. Numbers in brackets indicate number of launched molecules.

columns exhibit their diffusion by country at the end of the period. We already have a preliminary evidence that a certain persistency exists for the first locations, with two thirds of the new chemical compounds marketed for the first time in Germany or the $\mathrm{UK}^{16}$, although diffusion of the same compounds is eventually more uniform at the end of the period. Yet, Germany is still the country where more launches occur, whereas in Portugal and Belgium there is a smaller portfolio of launched products.

In Figure 3, we concentrate on the sequence of country launches. As Germany is the country with the highest share of first launches, we take it as reference to observe the median sequence, potentially taking only 274 (out of a total 304) molecules that were launched at some time in Germany and reached also other destinations in Europe. Hence, in Figure 3, on the vertical axis we measure the median delay of each country from launch in Germany, between a first and second quartile. In brackets, on the horizontal axis, we also provide by country the number of molecules that were launched both there and in Germany.

We observe two important stylized facts.

First, over our median sequence of launches there is a high degree of heterogeneity in access to medicines. In many cases a molecule can reach a further country more than two years after launch in Germany. In further launches, Austria, United Kingdom, Finland and Ireland have a narrower distribution of lags, with a lower difference between the first and third quartile, when compared for example to Poland, Czech Republic or Hungary, where besides some molecules that are launched after three of four months we find evidence of delays of two years.

Second, the diffusion of medicaments for patients by country is also heterogeneous. As already observed in Table 4, the diffusion of new molecules can range from $38 \%$ in Portugal to $90 \%$ in Germany. Eventually, only $19 \%$ of new molecules eventually reach all 15 sample countries, whereas about $25 \%$ of new molecules still linger in the country where we observe first launch, typically Germany and UK.

We clearly have a problem of time censoring until now, as a drug in our sample can be launched later in our timeline of analysis, for which we have less time to observe further country launches. To

\footnotetext{
${ }^{16}$ Both Germany and UK have substantially revised pricing policy in our period of analysis. In principle, Germany permits free pricing of on-patent drugs, while price regulation mainly relates to the way in which medicines are reimbursed (Nolte and Ruggeri, 2013). It does not apply an external reference pricing scheme, although in 2011 an early benefit assessment has been introduced. The United Kingdom does not apply an external reference pricing rule, although it prefers a scheme for profit controls, periodically negotiated between the Department of Health and the pharmaceutical companies. The Scheme was updated in 2009 and, more recently, in 2013.
} 
control for time censoring, we visually report Kaplan-Meier (1958) estimates of survival functions ${ }^{17}$ by country in Figure 4, to represent the probability that a molecule has not been launched in a given country after a certain period of time, i.e. it 'survived' to a country launch. These estimates are nonparametric in nature, since they do not control for possible determinants of different time to launch. Still, they provide another snapshot of the heterogeneity of access to new medicines by country.

In Figure 4, we observe again remarkable differences across countries, already from the first months: a representative compound is more likely launched in Germany, UK and Austria earlier than in other countries. Notably, recent members of the European Union such as Slovakia, Czech Republic, Poland and Hungary register a higher probability to launch than for example France, Belgium, Italy and Spain. Probably not by chance, the latter countries also rely on regulations where a form of negotiation with companies plays an important role when launching a drug for the first time. In the end, there's only a $8 \%$ probability that a molecule already launched elsewhere is not sold also in Germany after eleven years, compared to $63 \%$ in Portugal, which together with Belgium and Italy is still above the 50\% probability value at the end of our sample period. A log-rank test rejects the null hypothesis of an equality of countries' survival functions.

As we want to check for the therapeutic relevance of newly marketed molecules, we borrow from Lanthier et al. (2013) a classification that includes three categories in descending order of innovative content: i) first-in-class; ii) advance-in-class; iii) addition-to-class.

First-in-class drugs exploit new pathways for the treatment of a disease, and we assume they are more beneficial for patients. Advance-in-class are drugs that are not first-in-class, but were granted priority review designation by the US Food \& Drugs Administration (FDA), as they were acknoledged to offer major advances in treatment. All other drugs are classified as simple additions-to-class, with the least therapeutic value for patients.

Finally, we have a subset of drugs that do not match with the list by Lanthier et al. (2013). In this case, we checked manually from reports of the European Medicine Agency that these are actually marketed only in EU sample countries. As they didn't submit to evaluation by FDA, we cannot assess their therapeutic value consistently with what done by Lanthier et al. (2013) and we will treat them separately in our following analyses.

In Table 5 we observe that the majority of both first-in-class and advance-in-class compounds are enlisted under the category 'Antineoplastic and immunomodulating agents' (ATC first-digit category L). In general, this anatomic therapeutic category collects also the majority of our sample launches. On the other hand, once looking at innovative categories that cut across therapeutic categories, the majority of new compounds falls under the simple addition-to-class column, as they were not considered major breakthroughs by pharmacological experts.

\subsection{Market integration, income, innovative content, and country delays}

We are now ready to investigate if the remarkable differences in launch delays observed until now, both across countries and within countries by innovative content, may be driven by European market integration, besides other local market and company characteristics.

For this purpose, we rely on a Cox (1972) proportional hazards procedure:

$$
h\left(t / X_{i k c}\right)=h_{0}(t) \exp \left(X_{i k c} \beta_{x}\right)
$$

where $h\left(t / X_{i k c}\right)$ is the hazard rate for the $i$ th molecule classified in the therapeutic category $k$ and possibly launched in country $c$.

In the vector $X_{i k c}$ of determinants we include: i) the rate of pharmaceutical price convergence estimated after eq. 4 for each therapeutic market (ATC, 3-digit classification); ii) two binary variables

\footnotetext{
${ }^{17}$ We follow the classic non-parametric procedure set by Kaplan and Meier (1958), also known as the product limit estimate of survival functions: $\widehat{S}(t)=\prod_{j / t_{j} \leqslant t}\left(\frac{n_{j}-d_{j}}{n_{j}}\right)$, where $n_{j}$ is the number of new molecules that can be launched at time $t_{j}$, and $d_{j}$ is the number of launches at time $t_{j}$. The product limit is calculated over all observed launches before $t$. We calculate each product separately by country. These estimates are non-parametric in nature, since they do not control for possible determinants of different time to launch. They provide a first snapshot of the survival heterogeneity by country.
} 
Figure 4: Survival to launch by country, Kaplan-Meier estimates.

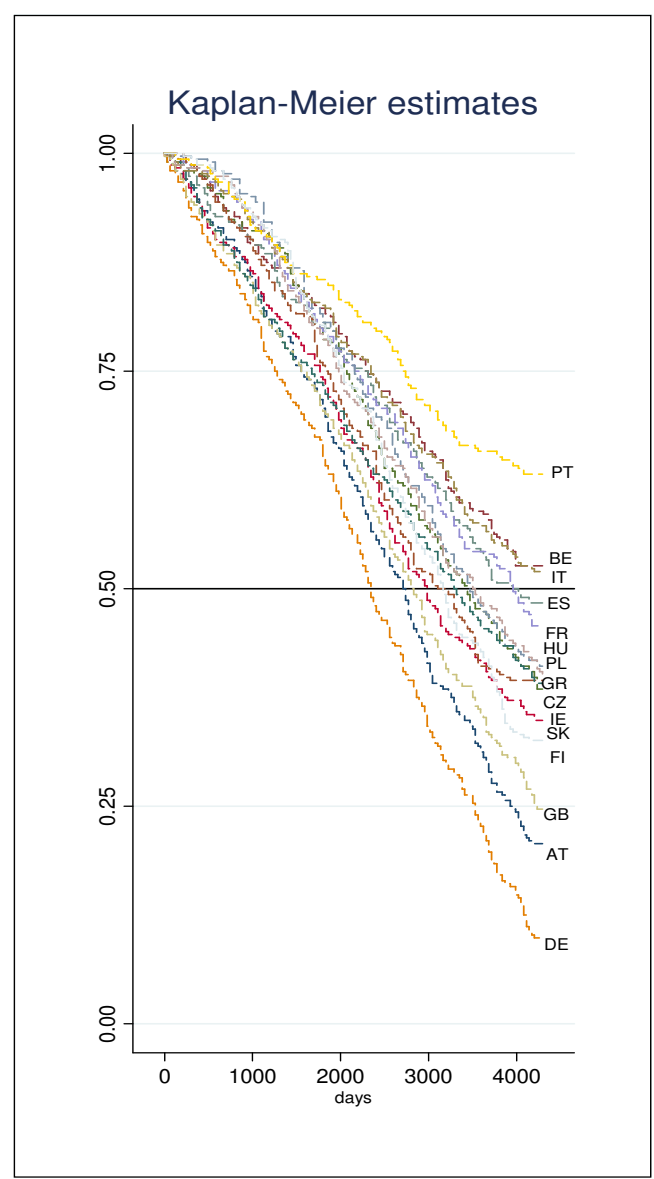

indicating whether the molecule is considered first-in-class or advance-in-class, following Lanthier et al. (2013); iii) the Purchasing Power Parity (PPP) of each country $c$ towards the rest of the EU $($ EU27 $=100)$, sourced from Eurostat; iv) levels of country $c$ real income (GDP) per capita; v) expectations on prices and on volumes, proxied (in logs) by average prices and volumes of already marketed molecules within the same $k$ therapeutic submarket (see also with Danzon and Epstein, 2012); vi) company sales in the $k$ th therapeutic reference market, as a proxy of the company's bargaining power against regulatory authorities in country $c$.

On the left side of Table 6 we report hazard ratios of nested specifications, whereas on the right side the reader can find corresponding coefficients before exponentiating. A hazard lower than one (i.e. a negative coefficient) implies a later-than-average launch, because the probability to survive to market launch is higher than a representative in-sample medicine.

The speed of price convergence of each therapeutic submarket shows a statistically significant correlation with hazard ratios for launches, which is robust to the inclusion of controls in all specifications. A percentage point of increase in speed of price convergence decreases the probability of a country launch by $(1-.873) \approx 13 \%$. This relationship is even stronger in the case of molecules that are considered most innovative for the treatment of diseases $(1-.799) \approx 20 \%$.

This result is consistent with the idea that companies have a disincentive to launch when the race to the Law of One Price is too fast and hence expected profit margins are lower. The statistical pattern is clear from the first panel of Figure 5, where we visualize the post-estimation survival functions by highest and lowest speed of convergence found in our sample distribution. Molecules that fall into 
Table 5: Innovative content of new active ingredients, based on a classification by Lanthier et al. (2013)

\begin{tabular}{|c|c|c|c|c|c|}
\hline Anatomic Therapeutic Classification & Addition & Advance & First & Unmatched & Total \\
\hline A -Alimentary tract and metabolism & 10 & 1 & 4 & 13 & 28 \\
\hline B - Blood and blood forming organs & 5 & 3 & 3 & 10 & 21 \\
\hline C- Cardiovascular system & 14 & 3 & 8 & 12 & 37 \\
\hline D - Dermatologicals & 2 & 0 & 5 & 7 & 14 \\
\hline G - Genito-urinary system & 12 & 0 & 1 & 11 & 24 \\
\hline \multicolumn{6}{|l|}{ H - Systemic hormonal preparations, } \\
\hline J - Antiinfectives for systemic use & 12 & 12 & 8 & 2 & 34 \\
\hline \multicolumn{6}{|l|}{ L- Antineoplastic and } \\
\hline immunomodulating agents & 8 & 18 & 27 & 10 & 63 \\
\hline M - Muscolo-skeletal system & 2 & 0 & 4 & 10 & 16 \\
\hline $\mathrm{N}$ - Nervous system & 14 & 1 & 4 & 14 & 33 \\
\hline \multicolumn{6}{|l|}{ P - Antiparasitic products, insecticides } \\
\hline and repellents & 0 & 0 & 0 & 1 & 1 \\
\hline R - Respiratory system & 4 & 0 & 1 & 8 & 13 \\
\hline S - Sensory organs & 4 & 6 & 1 & 3 & 14 \\
\hline Total & 87 & 44 & 69 & 104 & 304 \\
\hline
\end{tabular}

the highest convergent therapeutic classes have a probability of about $60 \%$ to survive to launches (i.e. only about $40 \%$ of probability to be launched).

Similarly, in the second panel of Figure 5 we report a visualization of estimates for survival functions by innovative content alone and in presence of average price convergence. There, we observe a clear ranking as most innovative drugs are on average launched later than advance-in-class, even more so in presence of price convergence.

The latter finding suggests that a problem of access to medicines, as a consequence of delays in launch and/or partial diffusion, is not limited to drugs that have already several competitors, and for which marketing might not be worth the fixed cost of market entry.

Rather, we argue, expectations of decreasing prices in the case of molecules that are more $R \& D$ intensive can be an additional deterrent for pharmaceutical companies, which may prefer to segment the market as long as possible, to harvest profits first where the expected prices are higher. Indeed, from our data we already observe that most of them (71 out of 96) are first launched in Germany, United Kingdom, and Finland, which are also the countries with the highest income per capita in our sample. We find a positive shift of the baseline hazard rate (i.e. a negative shift of the survival rate) when the income per capita is higher, which means that a representative molecule is launched earlier in richer countries than in poorer countries.

Moreover, first-in-class drugs are more difficult to evaluate at first country launches and this adds further delay to country launches. This is evident from the panel b) of Figure 5, where we plot post-estimation survival functions for first-in-class, advanced-in-class and first with convergence. The higher is the innovative content that the producer claims, the more difficult can take negotiations for pricing and reimbursement because there are fewer appropriate benchmarks than simple advance or addition to pharmacological classes.

Local market expectations, for demand and price, are in line with previous findings by Danzon, Wang and Wang (2005). The higher the expected prices and volumes, the higher the launch probability. Finally, larger and diversified companies tend to launch earlier since they have already experience of the market and its regulation. 
Table 6: Cox proportional hazards model for country launch delays

\begin{tabular}{|c|c|c|c|c|c|c|c|c|}
\hline $\begin{array}{l}\text { Dependent variable : } \\
\text { hazard rate of launch }\end{array}$ & Cox I & $\frac{\text { zard ratios }}{\text { Cox II }}$ & Cox III & Cox IV & Cox I & $\frac{\text { oefficients }}{\text { Cox II }}$ & Cox III & Cox IV \\
\hline pharma convergence & $\begin{array}{r}.881^{* *} \\
(.050)\end{array}$ & $\begin{array}{r}.879 * * \\
(.050)\end{array}$ & $\begin{array}{r}.911 * * \\
(.037)\end{array}$ & $\begin{array}{r}.873 * * \\
(.030)\end{array}$ & $\begin{array}{r}-.127 * * \\
(.057)\end{array}$ & $\begin{array}{r}-.129 * * \\
(.057)\end{array}$ & $\begin{array}{r}-.093 * * \\
(.040)\end{array}$ & $\begin{array}{r}-.135^{* * *} \\
(.063)\end{array}$ \\
\hline first * pharma convergence & & & & $\begin{array}{r}.799 \% * \\
(.036)\end{array}$ & & & & $\begin{array}{r}-.223 * * \\
(.105)\end{array}$ \\
\hline advanced * pharma convergence & & & & $\begin{array}{l}.802 * \\
(057)\end{array}$ & & & & $\begin{array}{r}-.221 * \\
(.117)\end{array}$ \\
\hline purchasing power parity $(\mathrm{EU}=100)$ & $\begin{array}{r}.918^{* *} \\
(.009)\end{array}$ & $\begin{array}{r}.916^{* * *} \\
(.030)\end{array}$ & $\begin{array}{l}.933^{*} \\
(.034)\end{array}$ & $\begin{array}{l}.937 * \\
(.034)\end{array}$ & $\begin{array}{r}-.085^{* *} \\
(.033)\end{array}$ & $\begin{array}{r}-.088 * * \\
(.033)\end{array}$ & $\begin{array}{l}-.069 * \\
(.036)\end{array}$ & $\begin{array}{r}-.065 * \\
(.036)\end{array}$ \\
\hline (log of) GDP per capita & & $\begin{array}{r}1.158 * * * \\
(.051)\end{array}$ & $\begin{array}{r}1.145 * * \\
(.067)\end{array}$ & $\begin{array}{r}1.142 * * \\
(.072)\end{array}$ & & $\begin{array}{r}.146 * * * \\
(.044)\end{array}$ & $\begin{array}{r}.135 * * \\
(.059)\end{array}$ & $\begin{array}{r}.133 * * \\
(.063)\end{array}$ \\
\hline (log of) expected price & & & $\begin{array}{r}1.053^{* *} \\
(.019)\end{array}$ & $\begin{array}{r}1.053 * * \\
(.022)\end{array}$ & & & $\begin{array}{r}.051 * * \\
(.018)\end{array}$ & $\begin{array}{r}.052 * * \\
(.021)\end{array}$ \\
\hline (log of) expected volume & & & $\begin{array}{r}1.055 * * * \\
(.015)\end{array}$ & $\begin{array}{r}1.057 * * * * \\
(.016)\end{array}$ & & & $\begin{array}{r}.054^{* * * *} \\
(.014)\end{array}$ & $\begin{array}{r}.056^{* * * *} \\
(.016)\end{array}$ \\
\hline (log of) firm sales & & & $\begin{array}{r}1.064 * * * \\
(.015)\end{array}$ & $\begin{array}{r}1.061 * * * \\
(.016)\end{array}$ & & & $\begin{array}{r}.062 * * * \\
(.014)\end{array}$ & $\begin{array}{r}.059 * * * \\
(.015)\end{array}$ \\
\hline first in class & & & & $\begin{array}{l}1.007 \\
(.146)\end{array}$ & & & & $\begin{array}{r}.007 \\
(.145)\end{array}$ \\
\hline advanced in class & & & & $\begin{array}{l}1.226 \\
(.220)\end{array}$ & & & & $\begin{array}{r}.204 \\
(.179)\end{array}$ \\
\hline N. molecules & 304 & 304 & 304 & 304 & 304 & 304 & 304 & 304 \\
\hline N. events & 4,560 & 4,560 & 4,560 & 4,560 & 4,560 & 4,560 & 4,560 & 4,560 \\
\hline N. therapeutic class & 101 & 101 & 101 & 101 & 101 & 101 & 101 & 101 \\
\hline Errors clustered by therapy & YES & YES & YES & YES & YES & YES & YES & YES \\
\hline Likelihood ratio chi2 & $9.04 * *$ & $20.91 * * * *$ & $68.19^{* * * *}$ & $83.39 * * *$ & $9.04 * *$ & $20.91 * * *$ & $68.19 * * *$ & $83.39 * * *$ \\
\hline
\end{tabular}

Note: Hazard ratios on the left and coefficients on the right, delta method for clustered standard errors. Breslow method for tied launches. Here above, ${ }^{*},{ }^{* *}, * * *$ stand respectively for $\mathrm{p}<.100, \mathrm{p}<.050, \mathrm{p}<.001$, robust standard errors in parentheses.

\section{Conclusions}

In this paper we find that the race towards European market integration is correlated with a persistent divergence in access to medicines across countries. The faster the convergence towards the Law of One Price, the greater the delay in launches of innovative drugs, especially in countries with lower income per capita.

More in detail, we provide evidence that despite fragmented national pricing policies and regulations, convergence of pharmaceutical prices has been fast across Europe, albeit at a granular level it can differ across therapeutic areas and product segments.

We find that a faster cross-country convergence in pharmaceutical prices is detrimental to the welfare of patients/consumers. There are two main reasons why this may be the case. First, since prices in low-income countries are converging upwards, while prices in high-income countries are converging downwards, faster than actual income convergence, patients/payers from low-income countries are paying more for medicines, and this burden offsets the decline in prices paid by patients/payers in high-income countries. Secondly, if price convergence results in longer than expected launch delays, we have the paradox that European economic integration is negatively affecting patient access to medicines.

These two trends come with a distorted system of incentives for companies, which react by launching new drugs selectively by country and therapeutic markets. Although manufacturers would prefer to launch instantaneously their products in as many countries as possible, the regulatory environment 
Figure 5: Post-estimation: survival rates for most and least convergent markets, and by innovative content

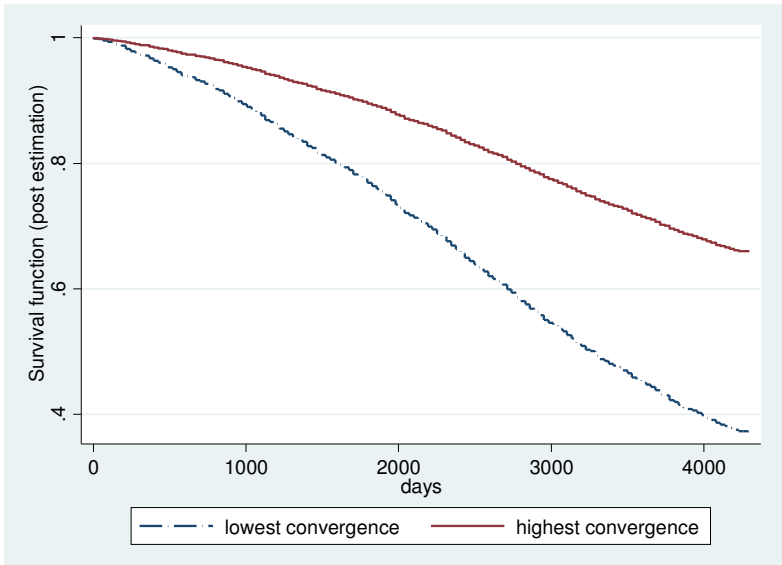

a) a range of survival rates between estimates for lowest and highest sample convergence

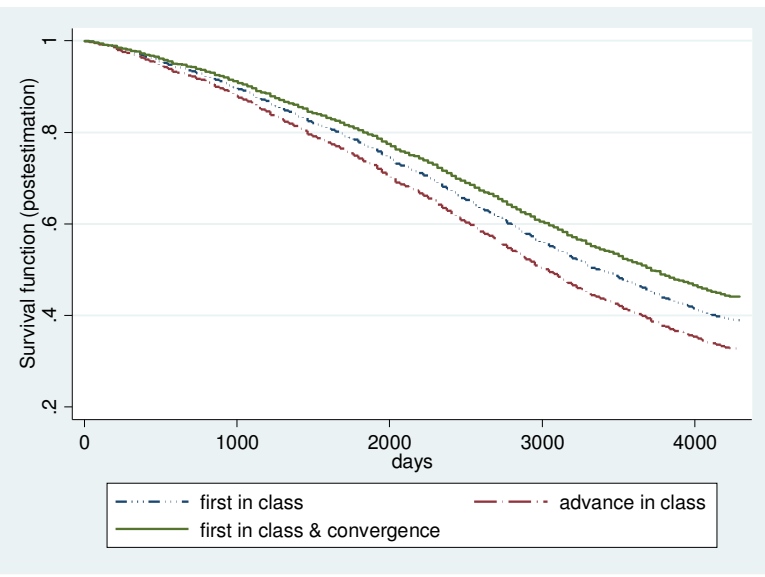

b) estimates by innovative content and sample convergence, at mean for first-in-class drugs

forces them to trade-off faster launches and larger market size with lower prices. Against this background, it is not surprising that launch delays are stronger for more innovative drugs, due to higher sunk costs in R\&D.

In general, it is a complex problem to find a way towards an efficient design for a pricing mechanism in presence of interdependent markets, when negative regulation spillovers among countries occur. Within the European Union, we argue, the negative spillovers are even more evident, since no trade barrier exists, while pricing and reimbursement decisions are responsibility of each Member State.

A first attempt towards a solution would be a stronger role for the European Medicine Agency (EMA) in producing guidelines for the therapeutic assessment of new drugs. It would already reduce part of the uncertainty of negotiations on this point, between pharmaceutical companies and national authorities. In the medium term, a policy that allows for a regulated price discrimination across Member States has to be considered a second best solution, as a legitimate consequence of different country demand and income characteristics. Therefore, companies and payers could segment markets together with a formula coordinated among countries, for example following the suggestion by Danzon et al. (2013) and Towse et al. (2015). In this way, a differential pricing system would at the same time improve patients'welfare, while taking into adequate consideration companies'economic incentives to recover from high $\mathrm{R} \& \mathrm{D}$ and marketing sunk costs. 


\section{References}

Campbell J. and Perron P. (1991). 'Pitfalls and Opportunities: What Macroeconomists should know about unit roots', NBER Macroeconomics Annual, vol. 6. MIT Press, Cambridge, MA.

Carone, G., Schwierz, C., and Xavier, A. (2012). 'Cost-containment Policies in Public Pharmaceutical Spending in the EU', European Economy - Economic Papers n. 461, European Commission.

Cavallo A., Neiman B. and Rigobon R. (2014). ' Currency Unions, Product Introductions, and the Real Exchange Rate', The Quarterly Journal of Economics, forthcoming.

Cecchetti, S., Nelson, M., Sonora, R. (2002). 'Price-level Convergence among United States Cities: Lessons for the European Central Bank', International Economic Review vol. 43(4) pp. 1081-1099.

Danzon P. M. and Chao L-W. (2000). 'Cross National Price Differences for Pharmaceuticals: How Large and Why', Journal of Health Economics, vol. 19, pp. 159-195.

Danzon P. M. and Epstein A. J. (2012). 'Effects of regulation on drug launch and pricing in interdependent markets', Advances in Health Economics and Health Service Resources, vol. 23, pp. 35-71.

Danzon P. M. and Furukawa M. F. (2011). 'Cross-national Evidence on Generic Pharmaceuticals: Pharmacy vs. Physician-drive Markets' NBER Working Paper Series N. 17726.

Danzon P. M. and Towse A. K. (2003). 'Differential Pricing for Pharmaceuticals: Reconciling Access, R\&D and Patents', International Journal of Health Care Finance and Economics vol. 3(3) pp. 183-205.

Danzon, P. M., Towse, A. K., and Mestre-Ferrandiz, J. (2015). 'Value-Based Differential Pricing: Efficient Prices for Drugs in a Global Context', Health Economics vol. 24, pp. 294-301.

Danzon P. M., Wang R. and Wang L. (2005). 'The impact of price regulation on the launch delay of new drugs evidence from twenty-five major markets in 1990s', Health Economics vol. 14, pp. 269-292.

Darvas Z. (2012). 'Real effective exchange rates for 178 countries: a new database', Bruegel Working Papers 2012/06.

Gambardella, A., Orsenigo, L., and Pammolli, F. (2000). Global Competitiveness in Pharmaceuticals: a European Perspective. Report for Directorate-General for Enterprise, European Commission. Brussels: European Commission.

Ganslandt, M., and Maskus K.E. (2004). 'Parallel imports and the pricing of pharmaceutical products: evidence from the European Union', Journal of Health Economics, vol. 23(5) pp. 1035-1057.

Goldberg, P. K. and Verboven, F. (2005). ' Market Integration and Convergence to the Law of One Price: Evidence from the European Car Market', Journal of International Economics vol. 65, pp. 49-73.

Grigoriadis, L. (2014). 'The Application of EU Competition Law in the Pharmaceutical Sector: The Case of Parallel Trade', European Business Law Review, vol. 25(1), pp. 141-201.

Hausman J. A. and MacKie-Mason J. K. (1988). 'Price Discrimination and Patent Policy', The RAND Journal of Economics vol. 19(2) pp. 253-265.

Jack, W. and Lanjouw, J. O. (2005). 'Financing pharmaceutical innovation: How much should poor countries contribute?' The World Bank Economic Review, vol. 19(1), pp. 45-67.

Kalbfleisch, J. D. and Prentice R. L. (2002). 'The Statistical Analysis of Failure Time Data', 2nd edition. New York: John Wiley and Sons.

Kanavos P. and Costa-Front J. (2005). 'Pharmaceutical Parallel Trade in Europe: Stakeholder and Competition Effects', Economic Policy vol. 20(44) pp. 751-798.

Kanavos P. G. andVandoros S. (2011). 'Determinants of branded prescription medicine prices in OECD countries', Health Economics, Policy and Law, vol. 6, pp 337-367.

Kaplan E. L. and Meier P. (1958). 'Nonparametric Estimation from Incomplete Observations', Journal of the American Statistical Association, vol. 53 pp. 457-481.

Kyle M. (2006). 'The role of firm characteristics in pharmaceutical product launches', The RAND Journal of Economics, vol. 37(3), pp. 602-618.

Kyle M. (2007). 'Pharmaceutical Price Controls and Entry Strategies', The Review of Economics and Statistics, vol. 89(1) pp. 88-99.

Lanjouw, J. O. (2005). 'Patents, Price Controls, and Access to New Drugs: How Policy Affects Global Market Entry', NBER Working Paper No. 11321.

Lanthier M., Miller K. L., Nardinelli C., Woodcock J. (2013). 'An Improved Approach to Measuring Drug Innovation

Finds Steady Rates of First-in-class Pharmaceuticals, 1987-2011,' Health Affairs, vol. 32(8), pp. 1433-9.

Leopold C., Mantel-Teeuwisse A. K., Vogler S., de Joncheere K., Laing R. O. and Leufkens H.G.M. (2013). 'Is Europe still heading to a common price for on-patent medicines? An exploratory study among 15 Western European countries', Health Policy, vol. 112(3), pp. 209-216. 
Levin A., Lin C-F. and Chu C-S. J. (2002). 'Unit root tests in panel data: asymptotic and finite-sample properties', Journal of Econometrics, vol. 108, pp.1-24.

Malueg, D., and Schwartz, M. (1994). 'Parallel imports, demand dispersion, and international price discrimination,' Journal of International Economics, vol. 37(3-4), pp.167-195.

McKelvey, M., Orsenigo L. and Pammolli, F. (2004). 'Pharmaceuticals analysed through the lens of a sectoral innovation system. In: Malerba F. (ed.) Sectoral systems of innovation. Cambridge University Press, Cambridge, MA.

OECD (2014). OECD Health Statistics 2014.

Parsley, D., Wei, S. J. (2001). 'Explaining the Border Effect: the Role of Exchange Rate Variability, Shipping costs, and Geography', Journal of International Economics vol. 55(1) pp. 87-106.

Ramsey, F. P. (1927). ' A Contribution to the Theory of Taxation', Economic Journal, vol. 37 pp. 47-61.

Rogers, J. (2007). 'Monetary Union, Price Level Convergence, and Inflation: how close is Europe to the United States?', Journal of Monetary Economics vol. 54(3) pp. 785-796.

Rogoff, K. (1996). 'The Purchasing Power Parity Puzzle', Journal of Economic Literature, vol. 34 pp.647-668.

Rogoff, Kennett, and Froot, Kenneth A., and Kim, Michael (2001). 'The Law of One Price Over 700 Years', IMF Working Paper N. WP/01/174.

Ruggeri, Kai, and Nolte, Ellen. (2013). 'Pharmaceutical Pricing. The Use of External Reference Pricing.', Rand Corporation.

Scherer, F. M., Watal, J. (2002). 'Post-TRIPS Options for Access to Patented Medicines in Developing Nations', Journal of International Economic Law vol. 5(4) pp. 913-939.

Schulenburg (von der) F. ,Vandoros S. and Kanavos P. (2011). 'The effects of drug market regulation on pharmaceutical prices in Europe: overview and evidence from the market of ACE inhibitors', Health Economics Review, vol. $1(18)$.

Szymanski, S. and Valletti, T. (2005). 'Parallel trade, price discrimination, investment and price caps,' Economic Policy, vol. 20(44), pp. 705-749.

Sutton, J. (1998). Technology and Market Structure. MIT Press. Cambridge, MA.

Towse A. , Pistollato M., Mestre-Ferrandiz J., Khan Z., Kaura S., and Garrison L. (2015). 'European Union Pharmaceutical Markets: A Case for Differential Pricing?', International Journal of the Economics of Business, vol. 22(2) pp. 263-275.

Tymur A. (2011). 'Pharmaceutical Price Convergence in the EU: Preliminary Results from the Panel Data Unit Root Test', Journal of Business \& Economics Research, vol. 9(10), pp. 35-46.

Zellner A., and Theil H. (1962). "Three-Stage Least Squares: Simultaneous Estimation of Simultaneous Equations," Econometrica, vol. 30(1), pp. 54-78. 


\section{Institution Markets \\ IMT}

INSTITUTE FOR ADVANCED STUDIES LUCCA

2016 ( ) IMT Institute for Advanced Studies, Lucca Piazza San ponziano 6, 5100 Lucca, Italy. www.imtlucca.it 